\section{Pervasive punishment in a pandemic}

\author{
Ryan Casey, Fergus McNeill (i), \\ Betsy Barkas, Neil Cornish, \\ Caitlin Gormley, \\ and Marguerite Schinkel
}

University of Glasgow, UK
Probation Journal 2021, Vol. 68(4) 476-492

(C) The Author(s) 2021

(c) (1) (5)

Article reuse guidelines: sagepub.com/journals-permissions DOI: $10.1177 / 02645505211050871$ journals.sagepub.com/home/prb

(SAGE

\begin{abstract}
In this paper, we draw on data from a recent study of how Covid-19 and related restrictions impacted on vulnerable and/or marginalised populations in Scotland (Armstrong and Pickering, 2020), including justice-affected people (i.e. people in prison and under supervision, their families and those that work with them; see Gormley et al., 2020). Focusing here mainly on interviews with people released from prison and others under community-based criminal justice supervision, we explore how the pandemic impacted on their experiences. Reflecting upon and refining previous analyses of how supervision is experienced as 'pervasive punishment' (McNeill, 2019), we suggest that both the pandemic and public health measures associated with its suppression have changed the 'pains' and 'gains' of supervision (Hayes, 2015), in particular, by exacerbating the 'suspension' associated with it. We conclude by discussing the implications of our findings for the pursuit of justice in the recovery from Covid-19.
\end{abstract}

\title{
Keywords
}

probation, parole, supervision, punishment, pandemic, Covid-19

\section{Introduction}

Between July and December 2020, the Scotland in Lockdown study explored how Covid-19 and related restrictions impacted on vulnerable and/or marginalised

\section{Corresponding Author:}

Professor Fergus McNeill, SCCJR, University of Glasgow, Florentine House, 53 Hillhead Street, Glasgow, G128QF, UK.

E-mail: Fergus.McNeill@glasgow.ac.uk 
populations in Scotland (Armstrong and Pickering, 2020). People in and around the justice system (people in prison, after release and on supervision, as well as their families) were one of the populations included (Gormley et al., 2020). In this paper, given the aims of this special issue of the Probation Journal, we focus mainly on how the pandemic impacted on people released from prison and others under community-based criminal justice supervision.

The first Covid-19 case in Scotland was reported on 1 st March 2020 and the first death was recorded 12 days later. On 20th March, the Scottish Government told cafés, pubs, and restaurants to close, and the first national 'lockdown' followed on 23rd March. Regimes of punishment and control were swiftly and dramatically impacted. On 25th March, all Sheriff Court business (and with it most criminal proceedings) was indefinitely adjourned, except for cases where the accused was in custody. These court closures created major backlogs in proceedings and, as we discuss below, effectively prolonged community sentences. Criminal justice social work (hereafter CJSW) moved swiftly to provision of remote supervision and support in most cases (i.e. via telephone contacts) and all unpaid work ordered as part of Community Payback Orders (the main community sentence in Scotland) was suspended. To manage the crisis in prisons, Covid-19 emergency measures (introduced by the Scottish Government and approved by the Scottish Parliament as the Coronavirus [Scotland] Act 2020) included an early release scheme. After some delay, the Scottish Prison Service also implemented virtual visits and began to issue mobile phones within prisons for the first time. For those that remained in prison for the duration of lockdown, most were confined to their cells for 2223 hours per day. Almost all other daily activities in prison were cancelled, including in-person visits, external services, education and library access, fellowship meetings and church services (though quickly replaced with recorded services), prison work parties, and gym access (for a comprehensive timeline of events relating to Scottish prisons and prisoners, see SPARC, 2021). People who were released (both through the early release scheme and through routine release processes) returned to a society that was profoundly altered, in previously unimagined ways.

Given the nature of the changes, both within Scottish society and in the justice system, it is not surprising that the analysis offered below suggests that the pandemic significantly changed how people experienced supervision. In general, for our study's participants, state supervision became less supportive and more residualised around risk management. At the same time, the specific pains of 'suspension', which have been associated with conditional forms of punishment in the community (McNeill, 2018; 2019; 2020), were significantly exacerbated, both for people directly under penal control and for their families. In response to these developments, some small grass-roots community organisations stepped up their provision of practical and emotional support in interesting and creative ways. Both these positive initiatives and our wider analysis of the pandemic's impact on supervision offer important lessons for the post-pandemic recovery.

In the next section, we summarise some previous work about the pains of punishment, especially within the community, before moving on to outline the methodology of our study. In presenting our findings, we discuss how the pandemic impacted on 
three key aspects of our participants' experiences; the support that people lost and gained, the loosening of the supervision to which they were subject, and ladmittedly, somewhat more speculatively) the complex relationships between penal severity and uncertainty revealed in their accounts. In our conclusion, we argue that reflecting on how the pandemic changed supervision can teach us important lessons about how to 'build back' towards a fairer and a safer society. Through this analysis, we hope to contribute not just to the emerging literature around how Covid-19 has changed punishment (for example, see Carr, 2020; Condirston, 2021; Dominey et al., 2020; Maycock, 2021; User Voice, 2020), but also to the wider public debate about what a 'just' recovery might require.

\section{The pains (and gains) of penal supervision}

Though Gresham Sykes' (1958) work on the pains of imprisonment has been much discussed and debated, it was not until 10 years ago that loan Durnescu (2011) first explored the 'pains of probation'. His study-based on interviews with probationers in Romania - revealed that, alongside deprivations of time and the other practical and financial costs associated with complying with the conditions of their sentences, limitations on their autonomy and intrusions into their privacy, probationers also reported the pain of the 'forced return to the offence' and, crucially in this context, the pain of a life lived 'under a constant threat' (that is, the threat of further punishment should they be found in breach of probation conditions).

Although it drew on a small number of interviews with supervisees and supervisors, Hayes' (2015) nuanced exploration of the pains and gains of probation in England revealed six sets of related pains: pains of rehabilitation, of liberty deprivation, of welfare issues and of external agency interventions, as well as process pains and pains associated with stigma. Importantly, some of these pains were intensified, some reduced and some unaffected by the nature of the supervisory relationship. Hayes (2015: 99-100) concludes that ' ${ }^{\prime} .$. whether at the level of policy or of individual practise, we must recognise supervised community penalties as systems of 'pain delivery', however benevolent the intention.' Other recent work in England and Wales (reviewed by Fitzgibbon and Healy, 2017) similarly paints a mixed picture of how supervision is experienced there. McNeill's (2012) review of Scottish research on experiencing supervision (based on a review of studies conducted in recent decades) also concluded that supervision is a highly variable and contingent experience. How it is constructed and experienced depends - at the micro-level - on the characteristics, attitudes and dispositions of both supervisee and supervisor, and - at the meso and macro levels - by the constraints and affordances generated by their social and cultural contexts.

In seeking to better understand and articulate the penal character of contemporary imprisonment in England, building on earlier work by Downes (1988) and by King and McDermott (1995), Crewe (2011) distinguished between the depth, weight, and tightness of imprisonment. Depth refers to degree of physical security to which one is subject and to the distance from release and from the outside world that this implies, represents, and constitutes. Weight refers to the 
psychological burdens of imprisonment; to how heavily it bears down upon prisoners. Tightness is the third dimension, which Crewe himself developed:

'The term 'tightness' captures the feelings of tension and anxiety generated by uncertainty (Freeman and Seymour, 2010), and the sense of not knowing which way to move, for fear of getting things wrong. It conveys the way that power operates both closely and anonymously, working like an invisible harness on the self. It is all-encompassing and invasive, in that it promotes the self-regulation of all aspects of conduct, addressing both the psyche and the body' (Crewe, 2011: 522).

In Crewe's analysis tightness is closely related to the indeterminacy of long-term sentences. For those whose liberation date is not automatic, progression and release depend on psychological and other assessments of risk and readiness; meaning that prisoners must conduct and present themselves in certain ways (see also Warr, 2020). Though focused on imprisonment, Crewe (2011) also mentions the 'tightening' nature of post-release supervision in the community. For those completing their sentences in the community under supervision, it is necessary to sustain the required performance, if recall to prison is to be avoided. That said, Crewe and levins (2021) have recently built upon the notion of tightness to better understand the ways in which and conditions under which the grip of punishment may instead be 'loose', sometimes due to systemic deficiencies.

Drawing on recent research using creative and ethnographic approaches, McNeill $(2018,2019)$ has explored how supervision (in Scotland and elsewhere; see Fitzgibbon, et al., 2017) is often experienced as entailing significant constraint, the loss or suspension of time and the imposition of judgement. Waste emerged as another key theme, whether in the sense of being treated as waste or of in the sense of dealing with waste. Supervision could also be experienced as a kind of lifescaffold that supported growth or development. Notably, four of these five aspects of supervisees' experiences involved both pains and gains (growth can be painful, constraint can provide comfort); only the experience of being judged and stigmatised was reported in entirely negative terms.

Analysing the experiences of penal subjects in the USA, Miller and Stuart (2017) have argued that being judged and placed within 'the supervised society' produces a distinct form of 'carceral citizenship' which has profound implications for its subjects; their civil rights are diminished, while their personal and civic responsibilities are heightened. They also gain access to certain kinds of services. Drawing on the recent studies mentioned in the previous paragraph, McNeill (2018) has similarly characterised supervision as being associated with civic degradation via what he terms the 'Malopticon'; meaning, a penal apparatus that sees the subject badly, that judges them to be bad, and which projects this negative appraisal into wider society. He argues that, similarly to the way that conditionality operates in welfare systems, the Malopticon produces disqualification from citizenship entitlements via the degradation of its subjects (McNeill, 2020).

But McNeill (2018) also argues that supervision is not always - and need not be Maloptical. To limit its negative effects and enhance its positive potential, McNeill 
(2019) argues that supervision should be used parsimoniously and proportionately; and developed and delivered so that it is practically helpful in its focus, fair and legitimate in its administration, and, crucially, time-limited in its impositions.

\section{Methodological note}

As we noted above, this paper draws upon data from a rapid research project, the Scotland in Lockdown study, which focussed on understanding the impacts of Covid-19 restrictions and measures on groups of people already experiencing exclusion, isolation, and marginalisation (Armstrong and Pickering, 2020). The study included people affected by criminal justice but also disabled people or those with long-term health conditions, refugees and people seeking asylum who were at risk of destitution, and people surviving domestic abuse or sexual violence. The study was funded by the Chief Scientist Office (hereafter CSO) as part of its Rapid Research in Covid-19 Programme. Ethical review and approval of the project was received via the College of Medical, Veterinary and Life Sciences at the University of Glasgow. The research was conducted and completed between July and December 2020 by a large team of researchers and supported by 20 partner organisations from the third sector.

Our criminal justice dataset includes 86 prisoner surveys 73 men, 11 women and 2 undisclosed), 20 prisoner letters (10 from women, 10 from men), 15 interviews with people under supervision and/or who had recently left prison, 6 interviews with family members of prisoners, and 11 interviews with members of staff in prisons, social work and third sector organisations. Recruitment for interviews with people in or after prison and/or on supervision, with family members, and with staff were arranged through partnerships with community-based organisations involved in the project, through online advertisements, and through advertisements circulated amongst CJSW staff. One partner organisation, the Scottish Prisoner \& Advocacy Collective (SPARC) also independently carried out 6 interviews with people with experience of being under criminal justice control. This data was made available to us and has been analysed alongside the interviews conducted by our researchers, as the questions and subject matters resonated with the interviews we carried out. Some staff interviews were also arranged as a follow-up interview to a broader organisation survey distributed online from August - October 2020 which captured perspectives of service providers working during the pandemic. All interviews were conducted by phone or online video calls which enabled a broad (but not wholly representative) geographical spread of participants including people residing most commonly in Edinburgh, Glasgow, Highlands, Inverclyde, and South Lanarkshire.

In this paper, we focus on the interviews with people subject to supervision in the community, but also draw on the wider dataset where appropriate. Those interviewed were subject to various community supervision orders/conditions, including Community Payback Orders, Orders for Lifelong Restrictions, Drug Treatment and Testing Orders, throughcare support, and electronic monitoring. The interviews were designed and analysed as part of the broader Scotland in Lockdown study; 
they were loosely structured via questions about how Covid-19 and the response to it had impacted on the lives of participants and their loved ones; we asked how the impact changed as the pandemic progressed and as the restrictions tightened and loosened. As the data collection progressed and the analysis began, through regular discussions among the large team of researchers involved, we developed a common coding framework (applied using NVivo software) which included perceptions of Covid-19 and associated risks, physical and mental health, social situations and impacts, housing situations and impacts, economic circumstances and impacts, service provision and access, safety and security, gender and other equality issues, routines and rhythms, emotional and practical responses to lockdown, technology and digital issues, isolation and loneliness, and any positives of lockdown. For staff interviews, we also coded data around organisational and personal impacts.

\section{Findings}

In broad terms, our analysis revealed that the experience of lockdown was both traumatising and punitive for people who were already marginalised and subject to criminal justice control and, by extension, for their families. In effect, the severity of sentences for people completing custodial sentences and community sentences increased. In Crewe's terms (2011), and as we will discuss below, their punishment become 'deeper' and 'heavier' but also sometimes less 'tight'. Crucially, both people in prison and people under supervision suffered extension to and exacerbation of the ways in which punishment suspends and disrupts their lives; their efforts to progress towards a life beyond punishment were often frustrated and stalled. For most of those we spoke to, statutory services offered significantly less support during the pandemic; but community groups and grassroots organisations worked with commitment and creativity to fill gaps and respond to needs.

\section{Losing (and finding) support}

Regimes of punishment and control in the community were drastically impacted by the Covid-19 pandemic and lockdown measures. Key statutory services such as CJSW predominantly pivoted to remote telephone-based supervision, or less frequently, to communicating by letter, or via socially distanced home visits or outdoor meetups. While most staff reported that phone-based supervision imposed limitations on the supervisor-supervisee relationship, it was also evident that some staff felt that it gave them the opportunity to have more casual and sympathetic conversations with those they supervise, in contrast to the formalities of prepandemic face-to-face appointments. As one social worker, Susan, explained:

'The length of time that we have to talk to them isn't rigid now, you've been able to expand that. [...] Last week one of my clients, I was on the phone to her for an hour and a half. Now, ordinarily, we just have half hour appointments. An hour and a half, and her emotions were really, really, very tearful, very distressed, very upset. 
It's to do with the situation, people are in hostels and not being able to go out as much, and relationships, and a lot of tensions within the hostel. So, you're managing things, in a half hour appointment, I wouldn't have even got there. It would have been, right, what's your drug use, you've been going to the pharmacy, this is...? You know, you're just sort of working through stuff and doing risk assessments, much more precise. Whereas this way, you've been having more sort of general conversations that probably the Resource Worker would have had. It is about how people are managing, you know, and about giving people permission that they are allowed to just be low, fed up, not motivated. And it can go up and down'.

Social workers like Susan saw this change in supervision as a way to creatively carry out their work despite the suspension of most face-to-face meetings and broader lockdown restrictions. But despite such efforts, from the perspectives of most people under supervision, these changes nevertheless felt like a withdrawal of statutory support and oversight. For example, Tim shared how the phone calls were not enough to substitute for the in-person meetings and groupwork support he previously received:

'Just before we went into lockdown, I was attending a group as part of my order, I was seeing my social worker once every couple of weeks, and things were going okay [....] I mean, I felt in a good place then [...] But then the lockdown happened, so then I had to stop going to my group, and I was always hearing from my social worker like once a fortnight by phone [...] seeing how I was, and I'd be lying if I'd said my mental health wasn't affected'.

For those like Tim that needed more than a light-touch phone check-in, the lack of statutory support exacerbated feelings of isolation. Recalling the conceptualisation above of imprisonment's 'depth', which refers to the varying degrees of distance from life outside that prisoners endure, Tim's experience suggests that, for some people under supervision, physical presence within the community need not entail proximity to or engagement with it.

Of course, for all of us, lockdown and social distancing affected such engagement. But the restrictions were not uniform in their effects. As many third sector and community-based organisations switched to online support and digital services, some people under supervision struggled to navigate their way towards using mobile and digital technologies, if indeed they could make that transition at all. The Covid-19 pandemic has highlighted and intensified the need to be connected via online resources and devices, as Zoom meetings, WhatsApp groups, online booking systems, QR codes, and supermarket delivery slots all came to be mediated by the internet. However, as Lewis shared, the conditions of his supervision prohibited him from using the internet, which excluded him from access to basic services and support:

'Unfortunately, one of the parts of my licence is that I don't have the Internet. So, life without the Internet is the worst part. [...] you're very restricted. If you haven't got the Internet nowadays, you don't realise how much of your life you can do via the 
Internet. You know, from basic ordering food to ordering a TV or ordering books or buying books online or...you know, whatever'.

Even for those not formally excluded from the internet via licence conditions, digital inequalities and data poverty produced or compounded social marginalisation, particularly during the Covid-19 pandemic. As Lucas et al. (2021) found in their study of data poverty in Scotland and Wales, the pandemic has exposed a digital divide between those who can afford stable and sufficient mobile/broadband data and those who cannot. The findings from the wider Scotland in Lockdown study support this, as digital inequalities played a significant role in determining whether people (across all groups) could access services that moved online (Armstrong and Pickering, 2020).

Staff from community-based organisations, such as Dave (below), quickly realised the importance of the relationship between digital connectivity and support:

'Some of them didn't have mobile phones. And especially the guys leaving prison, we thought it was very important to have their liberation pack put together for them so that when they were leaving, they could phone us straightaway and we could signpost them, we could help them access benefits, we could help them to register with their GP. And all the practical things that people need done for them, especially during lockdown when everybody was restricted and couldn't go into these places'.

Those released from prison during the pandemic, then, were released from locked down prisons to locked down communities in which many aspects of everyday life had suddenly moved online. In many respects, recalling the conceptualisation of imprisonment's depth and weight discussed above, even on the outside, many former prisoners remained isolated from social life and burdened by their exclusion. Crucially, for a range of reasons, many continued to suffer the exclusion from digital life characteristic of imprisonment, thus struggling to access the means most of us used to moderate lockdown's isolating effects. In sum, some of the depth and weight of lockdown imprisonment travelled into the community with them.

Recognising this, community groups and grassroots organisations responded by taking on new and demanding roles during the pandemic, working intensively and creatively to fill the gaps in support left by the statutory sector. The urgency of addressing post-release isolation was apparent in their accounts: to paraphrase one community-based staff member, support shifted from keeping people out of the criminal justice system to just keeping people alive. Beyond the supportive phone calls and helping people to get registered with a GP or bank, providing mobile phones and electricity/mobile top-ups, and distributing food parcels became crucial forms of support for people under supervision.

It is worth noting, however, that the isolation of lockdown did not affect everyone in the same way. In one, admittedly exceptional, case, a woman who was the subject of a Community Payback Order reported that, having recently given birth and embarked on recovery from drug dependency, lockdown provided a perfect opportunity to withdraw from social networks associated with her drug use and 
her offending. Regular and frequent phone contact from her social worker helped her to sustain her recovery and to adjust to her changed circumstances.

\section{Loosening supervision}

If, for most people, phone-based supervision meant a diminution in the care that they received, it also meant a reduction in the 'tightness' of the grip of penal control. Particularly for those who were concerned about the ever-present threat of a breach or recall to custody for non-attendance, the advent of remote contact was welcomed. For example, this loosening led one person under post-release supervision to report that he had gained freedom from CJSW oversight and could just 'go through the motions' by phone.

For supervisors, of course, this loosening of their grip created anxieties and challenges. The management of risk became an even more central concern. As one social worker put it, '[t] he people I've got to keep in touch with [...] I know I've got to keep in touch with them because they represent one thing, i.e., a risk to community safety. They get kept in touch with'. By extension, sustaining contact with those deemed less risky to others became a lower priority. However, in some cases, that was also associated with increased concerns for their welfare and safety; concerns which were very difficult to navigate at a distance: 'So, we are literally talking to someone, which is really difficult, because you're also not seeing the signs of the drug taking, or the upset or anger or frustration, or anything like that, you're just talking to someone'. (Susan). More generally, some social workers expressed frustrations around not knowing what was going on in people's lives and wanting people under supervision to share more, so that appropriate help could be offered.

For others, in line with the social workers' preoccupation with risk to others, people under supervision reported that contact seemed less focused on support and more on risk management. The lockdown intensified their sense of the coerciveness of this contact (in the name of public/community safety). For example, if someone missed an appointment (in person or by phone) pre-Covid-19, the first response was typically a welfare home visit by the supervisor, and then only if there was still no contact would the matter escalate. During lockdown, as explained by one statutory worker, responses to non-compliance escalated much more quickly, including via police involvement:

'Initially, we would check in with the clients by phone, regularly, see how their mental health was doing, how they were coping, let them know that they can contact us at any time. The only thing I would say was different was if we were concerned about them, we couldn't do the home visit. We had to contact the police and get the police to do a welfare check'. (Marie)

Not surprisingly therefore, for people under supervision, sharing too much during those calls could be seen as risky for them because it could cause concern or alter their supervisor's risk assessments and thresholds. Sensitivity to this dynamic 
created complex dilemmas around what to share and what not to share (perhaps explaining the frustration reported by the social workers and mentioned above). As Harry, who was under post-release supervision, put it:

'I have got this image in my head, having looked at the LS/CMI [the risk assessment tool] and looked at all the scores and the scoring tools and just seeing how they do it, ken, I just...I look at it like levels on an old stereo. Well, if you put this up there, then all that jumps up. If you put this here, this goes down. And every time I just say, well I don't want to move one button on my risk because everything else is kind of like... it's a nice ambient low risk sitting there that's just fine. And I want to maintain that for as long as I can. That's why I don't want to push the fucking treble up too much on this one issue in case it upsets this and all of a sudden, it's oh we're getting closer to mid-level. Maybe we should have fortnightly meetings or maybe we should actually revisit this and put this back in place, or I want you to do this now if this happened. I want you to do this now if this happens. [...] 'Cause all you want is for them just to fuck off and leave you alone, know what I mean. And you don't ever want to that to change. So, it's just about bonding and performing. Like, aye everything's fine'.

Some supervisees were concerned about a different kind of risk - the risk of Covid-19 infection. For those who continued to be required to report in person, presumably because they were deemed to present offending risks to others, there was no choice but to risk their health (and their family's health) in order to comply.

But for most supervisees, such as Stuart (below), the suspension of in-person, office-based supervision was a welcome development:

'You're hearing that being in, like, large groups and people breathing around you can lead to not just you dying, but you're killing your whole family. As soon as they say you don't need to go into that situation [in-person meetings with social workers] anymore, [...] straightaway you're like, right, that's perfect. That takes a whole area of anxiety out of your life because not going can lead to you going back to prison'.

Some also reported that, setting aside the question of reduced Covid-19 transmission risks, the informality of phone contact also changed the tone and quality of interactions, in a positive way:

'I can have quite a relatively light-hearted good check-in with [them] on the phone now, whereas I didn't really have that before'. (Colin)

Indeed, the unexpected opportunity to demonstrate that compliance and risk reduction could be sustained in the absence of face-to-face contact helped to win their supervisors' trust and, with it, a potentially sustained loosening of supervision's grip:

'They're talking about when they do go back to having visits, they've decided that I' $m$, kind of, at the risk category where it's low enough [...] that they'd be happy that even if they do start having visits again, they don't think I'd be one of the people that they need 
to get back down in a hurry. So...some of the change in practice is not having to engage with your social worker, your primary support in the community. Like, that's been a positive. [...] Because actually going into the office, whether it's just... it's the combination of everything. It's the time out of your life'. (Harry)

Some supervisors also recognised that CJSW offices, in general, were not welcoming environments and that Covid-19 suppression measures had made them even more alienating and stigmatising spaces:

'Clients used to be able to walk in, they could just walk in and say hi, sit down at reception, someone would come out and see them, they'd sit with other guys. Now they've got to stop at a revolving door, they've got to be checked off the list If they're not, they've got to sit outside, you know. But they see us coming in and out. We've got key cards. [...] We're going in a steel-gated door. It's a steel-gated building. Do you know what I mean? In a system where you're trying to... In a system where you know that the key to helping people move on and reducing reoffending is the building of relationships, why would you then design into the very architecture something which defines you as separate?' (Duncan)

Duncan's account of the social work office itself as an architecture of exclusion (cf. Phillips, 2014) stood in sharp contrast to the more positive atmosphere generated by the simple innovation of substituting an office visit with going for a walk or a coffee together:

'Sometimes we, you know, there are occasions when the weather is nice, and we feel that it's necessary that we do take the client out for a walk. We feel, most of the time, that we get more out of the client when we take them out of the office. The office is quite clinical. They don't feel relaxed in the office. Sometimes we get our best results when we actually take them away from the office and go for a walk or take them for a coffee'. (Marie)

At least for some supervisees and supervisors then, the loosening of supervision's grip (and of the national standards, rules and regulations that also grip practitioners) has been associated with unexpected and positive changes in their relationships and encounters. The intriguing effect may have been to make remote supervision feel more human/e and less burdensome; and hence more tolerable. Certainly, exercising less control and offering more trust seems to have been positive and productive, at least in some cases.

\section{Enduring uncertainty}

We noted above that, in relation to penal supervision, McNeill (2019) added 'suspension' as a fourth dimension to Crewe's (2011) account of the 'depth, weight and tightness' of contemporary imprisonment. The discussion of our findings thus far suggests that, for most people, the lockdown exacerbated supervisee's continuing exclusion from civic life; making their social isolation feel deeper and heavier. To put it 
another way, supervisees sank further from the surface of social life - even more than they would have in ordinary circumstances. For those most in need of support, for example, immediately after release from prison, this isolation was significantly exacerbated by their continuing digital marginalisation, sometimes to the detriment of their mental health and wellbeing. On the other hand, the loosening of supervision's grip brought some unexpected benefits.

Crucially, the concept of 'suspension' draws our attention to the ways in which people subject to penal power are compelled to endure uncertainty, particularly in relation to the precise duration and the terms of their punishment. The evidence we gathered suggests that the lockdown's impact on criminal justice processes greatly increased this uncertainty. This effect was perhaps strongest in relation to those still in prison, where the extreme paucity of prison regimes effectively stalled any possible progression towards release (unless release was automatic). People in prison on remand or in the community released on bail faced similar delays, such as Ross:

'It's been a tough time especially with that court case looming over me like I just want to get it over with, do you know what I mean, just to get past that stage'.

It is perhaps less well and widely understood that - even for those already released and/or serving community sentences - progression towards the easing of restrictions and the termination of supervision remains key concerns: '...I was supposed to be getting reviewed and obviously the review didn't take place because of all this.' (Harry). More generally, the position in relation to Community Payback Orders and other community sentences involving reviews/completions in front of a Sheriff - especially those with unpaid work requirements - caused a great deal of confusion for several months. One social worker tried to explain as follows:

'So [...], say an Order ended in May, that Order still ended in May. But the final review might not have been heard until September, until this month. So, you had this weird situation, where officially an order has finished, but the person remains in contact with us, until they've gone to court again properly for the Sheriff to say, that is it ended now. [...] So, Orders have finished, Orders have not been prolonged, but in a sense, they have been prolonged, but not officially, does that make sense?' (Susan)

To clarify the legal position, the Coronavirus (Scotland) Act (which contained a series of emergency measures relating to all areas of government and public service) came into force in April 2020. It immediately suspended all (then) existing unpaid work and 'other activity' requirements. All orders were extended by 12 months. This automatic extension also applies to new CPOs passed up until 30th September 2021. By the summer of 2020, the Scottish Government had accepted in principle that the accumulating backlog of unpaid work hours had to be addressed and, on 28th January 2021, it was announced that the required hours would be reduced by 35 per cent across all cases, except for those sentenced for domestic abuse, sexual offences, and stalking. The Government stated that: 
'Those categories of CPOs have been excluded to mitigate potential risks to future reporting of these offences, recognising ongoing work over many years by victims organisations, justice partners, government and others to remove the barriers that exist in relation to those offences' (see: https://www.gov.scot/news/community-paybackorders/, accessed 16th June 2021).

Given that it is not at all obvious how deferring or reducing the hours of unpaid work might affect reporting of these kinds of offences, the logic of their exclusion from the reduction in hours is perhaps unclear. What it perhaps reveals is the fact that the rationale for this measure was purely pragmatic; it arose from a concern not with parsimony or proportionality but from the profound practical challenges arising the accumulating hours of unpaid work. Notably, the undeniably punitive effect of the extension of the supervision period is not mentioned at all, far less justified.

Equally intriguingly, although the Scottish Government has made some limited use of its early release scheme, no provision has been made for reducing sentence lengths for people imprisoned in much more difficult conditions than they, the courts, or the Government could have anticipated. Indeed, given the evidence we have reported above, for those whose sentences did not or do not entail automatic release, they are very likely not only to have suffered much worse conditions in prison, but also to suffer prison for longer than might have been the case if there had been no pandemic.

So, while 35 per cent less unpaid work is now being asked of some people subject to CPOs, they will suffer an extension of the duration of their punishments; and the same is likely to be true for many long-term prisoners. For those under supervision in the community, progression may also have been delayed. Thus for all three groups, in different ways and to different degrees, the suspension and uncertainty created by punishment have been exacerbated, and no attention whatever seems to have been paid to the de facto increased severity of their sentences.

\section{Conclusions: building back fairer?}

The UK Government has had much to say about the need for 'building back better' after the pandemic. We think that our study offers some insights into how we can and why we must 'build back fairer' if we also want to 'build back safer'.

Firstly, our findings, both on the loss of support that many supervisees suffered and on the ways in which small community organisations innovated to meet their needs, reveal the importance and the value of developing, funding, and working with communities (and not just 'services') that can respond swiftly and effectively to the urgent material, social and emotional needs of those leaving prison with or without formal supervision, and of some of those serving community sentences. After all, it is in communities (and not by services) that we are all integrated, or from which we are dis-integrated. Certainly, for so long as state supervision remains preoccupied with and residualised around risk management, reintegrative 
support will likely happen elsewhere - but only if resources are provided to make that support sustainable.

Secondly, the digital exclusion of people in and after prison, and in communities affected by poverty, needs to be urgently addressed, along with issues of data poverty. It seems very likely that, even post-pandemic, more and more of our lives will be mediated through digital means. We would argue that it is neither an inevitable nor a desirable consequence of imprisonment that people's digital lives should be completely ended or suspended. Indeed, as the pandemic has taught us, digital inclusion is one means by which the collateral consequences of punishment (for families as well as prisoners) may be reduced; it must therefore be a key priority for any Government and any service committed to social reintegration.

Thirdly, the loosening of the grip of supervision seems to have produced some unexpected benefits. Particularly for some people subject to post-release supervision, phone check-ins, fewer office visits, and meeting up outside had the effect of humanising both their supervisors and their supervision. Yet, as one of our research partners noted on reviewing this paper, this loosening of supervision could be double-edged:

'I'm really interested in the tension that arises between the supervisors feeling more anxious about a lack of contact on one hand and the relief felt by the supervisees. But then the trade off or cost to the supervisee is potentially sharper and more punitive action if something small comes up that would have been dealt with in house with just a home or office visit. It's like borrowing more freedom from a loanshark instead of a bank' (Scott McMillan, SPARC, personal communication, 5th August 2021).

Some people under supervision certainly seized the opportunity to demonstrate that more intrusive and demanding forms of supervision were not, after all, required. We are, of course, mindful that our sample size is much too small to allow us to generalise - and that we have no data on any 'costs' associated with the loosening of supervision. But this begs an interesting but very complex set of questions, not just about how the pandemic and the lockdown affected crime, but also about how pandemic-related changes in criminal justice activity (and inactivity) affected offending and re-offending. Though methodologically complex, surely it must be worth exploring whether reductions in certain criminal justice activities made society any less (or any more) safe.

That question leads us to our final point. We noted earlier in this paper that McNeill (2019) has argued that principles of parsimony, proportionality and productiveness should be carefully applied to the uses and forms of penal supervision; and that to be 'productive' supervision must be helpful, legitimate and time-limited. Our findings suggest that, while supervision's 'grip' on some of its subjects may have become less 'tight', and while less may have been demanded of some of those subject to unpaid work requirements, the social marginalisation associated with supervision has been exacerbated, and the pains of being suspended in punitive limbo have also been sharpened. 
Support provided by small community organisations has helped people survive the intensification of their struggles for both survival and integration, and a loosening of supervision has also helped some; perhaps even humanising the supervisory relationship and thus enhancing supervision's legitimacy. But unless the pandemic's intensification of the pains of exclusion and of suspension is recognised and addressed in policy and practice, any gains in legitimacy will very likely be shortlived. And unless communities are better resourced to support reintegration, then there will be no real prospect of building back fairer and safer.

\section{Declaration of conflicting interests}

The author(s) declared the following potential conflicts of interest with respect to the research, authorship, and/or publication of this article: Fergus $\mathrm{McNeill}$ is a member of the Editorial Board of the Probation Journal.

\section{Funding}

This work was part of the Scotland in Lockdown: Health and Social Impacts of Covid-19 Suppression for Vulnerable Groups in Scotland and was supported by Chief Scientist Office (Scottish Government) funding, Grant Number COV/GLA/ 20/12.

\section{ORCID iD}

Fergus McNeill (D) https://orcid.org/0000-0003-3547-6482

\section{References}

Armstrong S and Pickering L (2020) Left out and locked down: Impacts of Covid-19 lockdown for marginalised groups in Scotland. Available at: https://scotlandinlockdown.co.uk/ project-report/ (accessed 13 June 2021).

Carr N (2020) Community supervision and COVID. Probation Journal 67(2): 95-97.

Condirston E (2021) Lockdown learning: Exploring prison learners' experiences of prison education during the covid-19 lockdown. Howard League for Penal Reform ECAN Bulletin 47: 4-12.

Crewe B (201 1) Depth, weight, tightness: Revisiting the pains of imprisonment. Punishment \& Society 13: 509-529.

Crewe B and levins A (2021) 'Tightness', recognition and penal power. Punishment \& Society 23(1): 47-68.

Dominey J, Coley D, Ellis Devitt K, et al. (2020) Remote Supervision: Getting the Balance Right. Cambridge: Centre for Community, Gender and Social Justice and KSS CRC Research and Policy Unit. Available at: https://www.ccgsj.crim.cam.ac.uk/system/ files/documents/remote-supervision_0.pdf (accessed 17 June 2021).

Downes D (1988) Contrasts in Tolerance. Oxford: Clarendon Press.

Durnescu I (2011) Pains of probation: Effective practice and human rights. International Journal of Offender Therapy and Comparative Criminology 55(4): 530-545. 
Freeman S and Seymour M (2010) 'Just waiting': The nature and effect of uncertainty on young people in remand custody in Ireland. Youth Justice 10(2): 126-142.

Fitzgibbon W and Healy D (2017) Lives and spaces: Photovoice and offender supervision in Ireland and England. Criminology \& Criminal Justice 19(1): 3-25.

Fitzgibbon W, Graebsch C and McNeill F (2017) Pervasive punishment: Experiencing supervision. In: Carrabine E and Brown M (eds) The Routledge International Handbook of Visual Criminology. London: Routledge, 305-319.

Gormley C, Schinkel M, Barkas B, et al. (2020) Criminal justice involved. In: Armstrong S and Pickering L (eds) Left Out and Locked Down: Impacts of Covid-19 Lockdown for Marginalised Groups in Scotland, pp. 57-66. Available at: https://scotlandinlockdown. co.uk/project-report/ (accessed 13 June 2021).

Hayes D (2015) The impact of supervision on the pains of community penalties in england and wales: An exploratory study. European Journal of Probation 7(2): 85-102.

King R and McDermott K (1995) The State of Our Prisons. Oxford: Clarendon Press.

Lucas PJ, Robinson R and Treacy L (2021) Data Poverty in Scotland and Wales. London:

Nesta. Available at: https://www.nesta.org.uk/report/data-poverty-scotland-andwales/ (accessed 13 June 2021).

Maycock M (2021) Covid-19 has caused a dramatic change to prison life'. Analysing the impacts of the covid-19 pandemic on the pains of imprisonment in the Scottish prison estate. British Journal of Criminology azab03 1: 1-16.

McNeill F (2012) Experiencing offender supervision in Scotland, a literature review prepared for and published by the EU COST action IS1 106 offender supervision in Europe. Available at: https://www.academia.edu/s/90c05ale9a? source=link laccessed 18 June 2021 ).

McNeill F (2018) Mass supervision, misrecognition and the 'malopticon'. Punishment \& Society 21 (2): 207-230.

McNeill F (2019) Pervasive Punishment: Making Sense of Mass Supervision. Bingley: Emerald Publishing.

McNeill F (2020) Penal and welfare conditionality: Discipline or degradation? Social Policy \& Administration 54(2): 295-310.

Miller RJ and Stuart F (2017) Carceral citizenship: Race, rights and responsibility in the age of mass supervision. Theoretical Criminology 21 (4): 532-548.

Phillips J (2014) The architecture of a probation office: A reflection of policy and an impact on practice. Probation Journal 61 (2): 117-131.

Scottish Government (2020) Coronavirus (Scotland) Act. Edinburgh: Scottish Government. Available at: https://www.gov.scot/publications/proposed-extension-coronavirusscotland-act-2020-coronavirus-scotland-no-2-act-2020-statement-reasons-2/ laccessed 17 June 2021).

Scottish Prisoner Advocacy \& Research Collective [SPARC] (2021) Covid-19 updates. Available at: https://scottishprisoneradvocacy.com/covid-19-updates/ laccessed 13 June 2021$)$.

Sykes G (1958) The Society of Captives: A Study of A Maximum-Security Prison. Princeton, NJ: Princeton University Press.

User Voice (2020) The User Voice of Lockdown: People in Prison and on Probation Tell us Their Experience of the Covid - 19 Pandemic so Far. London: User Voice. Available at: 
https://www.uservoice.org/wp-content/uploads/2020/07/The-user-voice-of-lockdown. pdf (accessed 17 June 2021).

Warr J (2020) 'Always gotta be two mans': Lifers, risk, rehabilitation, and narrative labour. Punishment \& Society 22(1): 28-47. DOI: 10.1177/1462474518822487. 